\title{
Brain Docosahexaenoic Acid Status and Learning in Young Rats Submitted to Dietary Long-Chain Polyunsaturated Fatty Acid Deficiency and Supplementation Limited to Lactation
}

\author{
SALVADOR GARCÍA-CALATAYUD, CARLOS REDONDO, EVA MARTÍN, JOSÉ IGNACIO RUIZ, \\ MIGUEL GARCÍA-FUENTES, AND PABLO SANJURJO \\ Department of Pediatrics [S.G.-C., C.R., E.M., M.G.-F.], University of Cantabria, 39011 Santander, \\ Cantabria, Spain; and Unit of Infant Metabolism [J.I.R., P.S.], Department of Pediatrics, Hospital de \\ Cruces, 48903 Baracaldo, Vizcaya, Spain
}

\begin{tabular}{|c|c|}
\hline \multicolumn{2}{|c|}{ ABSTRACT } \\
\hline $\begin{array}{l}\text { N-3 fatty acid deficiency has been related to decreased doco- } \\
\text { sahexaenoic acid (DHA) and increased docosapentaenoic acid } \\
\text { (DPA) levels in brain and to learning disadvantages. The influence } \\
\text { of n-3 deficiency and supplementation on brain fatty acids and } \\
\text { learning were investigated in young rats. Newborn Wistar rats were } \\
\text { assigned to three groups of cross-foster mothers. The control group } \\
\text { (C) was nursed by mothers that received essential fatty acids during } \\
\text { pregnancy and lactation, and the deficient group (D) was nursed by } \\
\text { mothers that did not receive those fatty acids. The supplemental } \\
\text { group (S) had the same conditions as D, receiving an additional } \\
\text { DHA and arachidonic acid supplement during lactation. Cerebral } \\
\text { cortex and hippocampus fatty acid composition was examined using } \\
\text { thin-layer and capillary column gas chromatography, and learning } \\
\text { was measured by passive-avoidance procedure. D brains showed } \\
\text { low DHA and high DPA levels, but S brain composition was similar } \\
\text { to C. Learning in the S group was unaffected, but in the D group, it } \\
\text { was poorer than C. Learning was directly correlated with DHA } \\
\text { levels and inversely with DPA levels in brain. Low DHA and high } \\
\text { DPA brain levels both were correlated with poor learning. DPA }\end{array}$ & 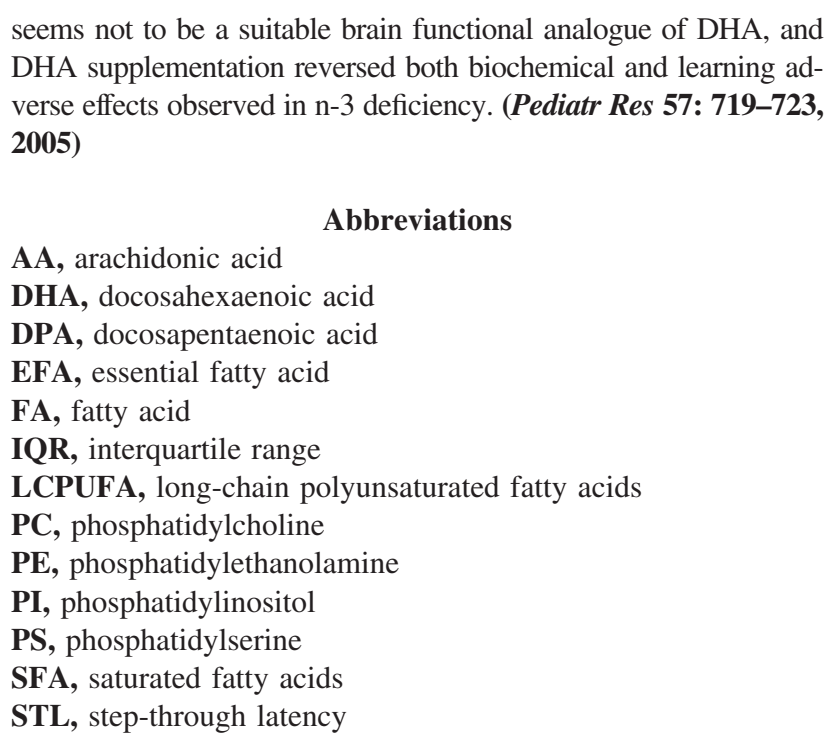 \\
\hline
\end{tabular}

Arachidonic acid (AA; 20:4 n-6) and docosahexaenoic acid (DHA; 22:6 n-3) are the major components of brain phospholipids and play a role in maintaining structural and functional integrity of membranes $(1,2)$. Mammalian brain accretes these long-chain polyunsaturated fatty acids (LCPUFA) derived from diet, especially during intrauterine and early postnatal life, and afterward, the adult brain has been described to be resistant to alter its fatty acid (FA) composition and tenaciously retains AA and DHA during n-3 and n-6 FA dietary deficiency $(3,4)$.

Received May 20, 2004; accepted September 3, 2004.

Correspondence: Salvador García Calatayud, M.D., Ph.D., General Dávila 306, portal

$1^{\circ}, 9^{\circ}$ C 39007 Santander, Spain; e-mail: garciacs@ono.com.

This work was supported in part by grants from MINER 293/96 and FISS 96/1279.

DOI: 10.1203/01.PDR.0000156506.03057.AD
Adult animals that were submitted to long-term dietary n-3 deficiency shared a similar FA profile in phospholipids of different tissues (5-7). This biochemical pattern has also been defined in young animals that were submitted to dietary n-3 deficiency in the prenatal and early postnatal periods $(8,9)$. This dietary n-3 FA deficiency profile consists of decreased levels of DHA and increased levels of 22:4 n-6 and 22:5 n-6 and the maintenance of the total n-3 plus n-6 FA in membrane phospholipids (10). Contrariwise, the FA profile of dietary DHA supplementation over a previous n-3 deficiency had also been described in different tissues (11-13). DHA deficiency is related to learning disturbances in humans (14) and rats (15), and, on the contrary, DHA supplementation is related to learning improvement in some animal models (16). The neurobiologic bases of learning and memory have been allocated to the neuronal network 
connecting the hippocampal formation to frontal cerebral cortex $(17,18)$.

The purpose of the present study was to assess the effects of dietary LCPUFA deficiency restricted to lactation on cerebral cortex and hippocampus biochemical FA profile and on retention memory in young rats. The hypothesis of reversing the adverse effects of LCPUFA deficiency during this period by means of dietary LCPUFA supplements was also tested.

\section{METHODS}

Animals and dietary schedules. Female Wistar rats (CRIFFA, SA, Barcelona, Spain) that weighed $80-100 \mathrm{~g}$ were housed in standard macrolon cages with controlled temperature $\left(21-23^{\circ} \mathrm{C}\right)$ and a 12 -h light/dark cycle. The animals were fed with a standard rodent diet that contained essential FA (EFA), before mating and throughout pregnancy and lactation. At parturition, litters were culled to eight pups, and newborn male rats were nursed for $3 \mathrm{~d}$ by their own mothers and then randomly assigned to be nursed by three groups of cross-foster mothers.

The control (C) group $(n=12)$ was nursed by non-EFA-deficient lactating rats that produced control milk, the deficient (D) group $(n=12)$ was nursed by EFA-deficient lactating rats that produced EFA-deficient milk, and the supplemented (S) group $(n=12)$ was nursed by EFA-deficient lactating rats and received additional LCPUFA supplement by gavage. The milk FA content of control and deficient milk was described previously (19). The LCPUFA supplement (Ordesa SL, Barcelona, Spain) composition was as follows: 16:0, $27 \% ; 18: 0,13 \% ; 18: 1 \mathrm{n}-9,38 \% ; 18: 2 \mathrm{n}-6,19 \% ; 20: 4 \mathrm{n}-6,2 \%$; and $22: 6 \mathrm{n}-3$, $1 \%$. Animals from the $\mathrm{C}$ and $\mathrm{D}$ groups were also gavaged and received the same volume of distilled water. The gavage procedure in the three groups was started at day 8 of life to ensure newborn pups' survival. The daily amount of LCPUFA supplement was progressively increased according to a previous model (19).

The dietary schedule was maintained for 3 wk until the end of lactation, and then all groups received a standard rodent diet that contained EFA. The protocol was approved by the Institutional Animal Research Committee, and the care of the animals was in accordance with ethical guidelines for animal research.

Tissue dissection and sample extraction. Animals were killed by decapitation at $42 \mathrm{~d}$ of age, and then cortex and hippocampus were dissected at $4{ }^{\circ} \mathrm{C}$. For membrane preparation, these brain areas were homogenized in buffer [10 $\left.\mathrm{mM} \mathrm{Na} \mathrm{PO}_{4} / \mathrm{HKH}_{2} \mathrm{PO}_{4}(\mathrm{pH}=7.4), 1: 10 \mathrm{wt} / \mathrm{vol}\right)$ and then centrifuged $(2000$ $\times g, 15$ min at $4^{\circ} \mathrm{C}$; Sorval, Kendro, Langenselbold, Germany, RC-5B). The pellets, which contained cerebral membranes, were resuspended in buffer. All samples were stored at $-80^{\circ} \mathrm{C}$ until lipid extraction was performed.

Lipid determination. Lipid fractions of different samples were extracted according to Folch (20). Phosphatidylethanolamine (PE), phosphatidylinositol (PI), phosphatidylserine (PS), phosphatidylcholine (PC), and sphingomyelin phospholipids were separated by thin-layer chromatography as described by Ruiz and Ochoa (21). Briefly, plates were developed in a step-wise manner in chambers that were saturated with 1) chloroform-methanol-water 65:40:5 ( $\mathrm{vol} / \mathrm{vol} / \mathrm{vol}$ ) to $4 \mathrm{~cm} ; 2$ ) ethyl acetate-isopropyl alcohol-ethanol-chloroformmethanol- $0.25 \% \mathrm{KCl} 35: 5: 20: 22: 15: 9(\mathrm{vol} / \mathrm{vol} / \mathrm{vol} / \mathrm{vol} / \mathrm{vol} / \mathrm{vol})$ to $11 \mathrm{~cm}$; and 3) n-heptane to $14 \mathrm{~cm}$. After the plate was sprayed with an ethanol solution of 2',7'-dichlorofluorescein, lipids were made visible under UV light. The bands were scraped and the FA were transmethylated following Lepage and Roy (22). Fatty acid methyl esters were separated and quantified on a Hewlett Packard GC 5890 gas chromatograph using a flame-ionization detector on a capillary column SP $2330(30 \mathrm{~m} \times 0.25 \mathrm{~mm}, 0.20 \mathrm{~mm}$; Supleco Company, Bellefonte, PA). The oven temperature was $80^{\circ} \mathrm{C}$ at injection, and this was maintained for $1 \mathrm{~min}$, then raised by $50^{\circ} \mathrm{C} / \mathrm{min}$ to $140^{\circ} \mathrm{C}, 5^{\circ} \mathrm{C} / \mathrm{min}$ to $190^{\circ} \mathrm{C}$ and maintained for $5 \mathrm{~min}$, and finally raised by $5^{\circ} \mathrm{C} / \mathrm{min}$ to $215^{\circ} \mathrm{C}$ and isothermal maintained for $15 \mathrm{~min}$. Injector and detector temperature was $250^{\circ} \mathrm{C}$. Helium was used as the carrier gas under a pressure of 0.5 bars. FA identification was performed by comparison with commercial standards $(\mathrm{Nu}$ Chek, Elysian, MN). Quantification of each FA was done by electronic integration. Results for FAs are expressed as weight \%.

Passive-avoidance test. The passive-avoidance test has been used widely to investigate learning and memory processes (23). The experiment was carried out using a step-through-type passive-avoidance apparatus (Letica S.A., Barcelona, Spain), consisting of an illuminated compartment $(20 \times 20 \times 20 \mathrm{~cm})$ and a dark compartment with a grid floor $(20 \times 20 \times 20 \mathrm{~cm})$, both separated by a guillotine door $(8 \times 8 \mathrm{~cm})$. In the training session, each rat was placed in the illuminated compartment and allowed $1 \mathrm{~min}$ for habituation. The guillotine door was opened and closed immediately when the animal entered the dark compartment. After $10 \mathrm{~s}$ for habituation, electroshocks $(0.3 \mathrm{~mA}-\mathrm{AC})$ were delivered through the grid floor for $3 \mathrm{~s}$ by a shock scrambler (LI100-26 Shocker; Letica S.A., España). In the test session, $24 \mathrm{~h}$ after the training session, each animal again was placed in the illuminated compartment. The step-through latency (STL) to enter the dark compartment was measured in both sessions, and the cut-off time was $600 \mathrm{~s}$.

Statistical analysis. The statistical analysis was performed by means of $t$ test and ANOVA for FA analysis and Mann-Whitney and Kruskall Wallis for data from the passive-avoidance test. The significance level was set at $p<$ 0.05. Correlations among FAs of different phospholipids fractions and between brain FAs and STL in the passive-avoidance test were made on the basis of Spearman correlation coefficients.

\section{RESULTS}

Cerebral cortex FA composition. In PE, the D group showed higher docosapentaenoic acid (DPA) and saturated fatty acid (SFA) levels than the $\mathrm{C}$ and $\mathrm{S}$ groups but lower levels of PUFA, n-3 PUFA, and DHA. 20:3 n-9 levels in the S group were lower than in the $\mathrm{D}$ group, but no differences were found compared with the $\mathrm{C}$ group. The $\mathrm{S}$ group presented lower SFA than the D group and presented DHA and total n-3 PUFA higher than the D and $\mathrm{C}$ groups (Table 1).

In PI fraction, the D group presented higher 20:3 n-9 than the $\mathrm{C}$ and $\mathrm{S}$ groups. The $\mathrm{S}$ group presented higher levels of PUFA, n-6 PUFA, and 20:4 n-6 than the C and D groups.

In PS fraction, the D group presented higher levels of 20:3 n-9, n-6 PUFA, and 22:5 n-6 and lower levels of n-3 PUFA and DHA than the $\mathrm{C}$ group. The $\mathrm{S}$ group was similar to the $\mathrm{C}$ group with higher levels of total n-3 PUFA and DHA and lower levels of total n-6 PUFA and DPA than the D group.

Hippocampal FA composition. In PE fraction, the D group showed higher levels of SFA, n-6 PUFA, 22:4 n-6, and DPA and lower levels of n-3 PUFA and DHA compared with the C group. The $\mathrm{S}$ group showed higher n-3 PUFA and DHA and lower SFA than the $\mathrm{C}$ group. Compared with the $\mathrm{D}$ group, the $S$ group showed higher DHA and total n-3 PUFA but lower SFA and total n-6 PUFA (Table 2).

In PI fraction, the D group presented lower levels of $n-6$ PUFA and AA but higher levels of 22:5 n-6. The $S$ group presented lower levels of SFA and higher levels of 20:3 n-9 and 22:4 $\mathrm{n}-6$. Compared with the $\mathrm{D}$ group, the $\mathrm{S}$ group showed higher AA, total PUFA, and total n-3 PUFA levels but lower DPA and SFA levels.

In PS fraction, the D group presented higher levels of $n-6$ PUFA and 22:5 n-6 and lower levels of n-3 PUFA and DHA. The $S$ group presented higher levels of 20:3 n-9 compared with the $\mathrm{C}$ group and higher DHA and lower DPA levels compared with the $\mathrm{D}$ group.

Passive-avoidance test. STL were similar among the three groups in the training test, but the retention trial, carried out $24 \mathrm{~h}$ later, showed significant differences (Kruskal-Wallis test, $\left.\chi^{2}=7.22, p=0.027\right)$. Analyzing medians and interquartile ranges (IQRs), the D group (66.0 s; IQR, 131) showed shorter STL than the C group (314.0 s; IQR, 472.7), and the S group (380.0 s; IQR, 430.7) showed no differences with the $\mathrm{C}$ group. All of these data state poorer memory in the $\mathrm{D}$ group than in the $\mathrm{C}$ and $\mathrm{S}$ groups and no differences between these last two groups (Fig. 1).

Correlations. The analysis of correlations between LCPUFA from cerebral cortex and hippocampus, and memory 
Table 1. Fatty acid composition of cerebral cortex $(\%, w t / w t)$

\begin{tabular}{|c|c|c|c|c|c|c|c|c|}
\hline Fatty acid & C group & D group & $S$ group & ANOVA & $p$ & C-D & C-S & D-S \\
\hline \multicolumn{9}{|l|}{$\mathrm{PC}$} \\
\hline SFA & $60.11 \pm 2.04$ & $59.37 \pm 2.41$ & $57.64 \pm 1.73$ & 4.51 & 0.02 & 0.40 & 0.01 & 0.05 \\
\hline$\sum$ PUFA & $13.61 \pm 1.35$ & $13.91 \pm 1.08$ & $14.58 \pm 0.92$ & 2.27 & 0.12 & & & \\
\hline n6-PUFA & $9.86 \pm 1.01$ & $10.34 \pm 0.75$ & $10.10 \pm 0.53$ & 1.04 & 0.36 & & & \\
\hline $20: 4 n 6$ (AA) & $6.40 \pm 0.65$ & $6.83 \pm 0.58$ & $6.93 \pm 0.49$ & 2.75 & 0.08 & & & \\
\hline $22: 4 n 6$ & $0.87 \pm 0.12$ & $0.90 \pm 0.13$ & $1.03 \pm 0.19$ & 3.66 & 0.04 & 0.60 & 0.01 & 0.05 \\
\hline $22: 6 n 3$ (DHA) & $3.59 \pm 0.49$ & $3.38 \pm 0.42$ & $4.30 \pm 0.55$ & 11.11 & 0.00 & 0.32 & 0.00 & 0.00 \\
\hline \multicolumn{9}{|l|}{$\mathrm{PE}$} \\
\hline SFA & $29.42 \pm 2.57$ & $31.65 \pm 2.65$ & $27.93 \pm 1.05$ & 8.27 & 0.00 & 0.02 & 0.10 & 0.00 \\
\hline$\Sigma$ PUFA & $57.26 \pm 2.23$ & $54.98 \pm 2.70$ & $57.95 \pm 1.54$ & 5.70 & 0.01 & 0.02 & 0.45 & 0.00 \\
\hline $20: 3 n 9$ & $0.22 \pm 0.05$ & $0.69 \pm 0.47$ & $0.31 \pm 0.13$ & 7.89 & 0.02 & 0.00 & 0.47 & 0.00 \\
\hline n6-PUFA & $31.25 \pm 1.67$ & $32.27 \pm 1.87$ & $30.60 \pm 1.06$ & 3.32 & 0.04 & 0.13 & 0.31 & 0.01 \\
\hline $22: 6 n 3$ (DHA) & $25.42 \pm 1.05$ & $21.67 \pm 1.61$ & $26.73 \pm 1.17$ & 47.29 & 0.00 & 0.00 & 0.02 & 0.00 \\
\hline \multicolumn{9}{|l|}{ PI } \\
\hline SFA & $47.06 \pm 2.71$ & $49.27 \pm 3.50$ & $46.35 \pm 2.11$ & 3.33 & 0.04 & 0.07 & 0.54 & 0.01 \\
\hline$\Sigma$ PUFA & $37.23 \pm 3.57$ & $37.58 \pm 3.68$ & $41.68 \pm 3.42$ & 5.75 & 0.01 & 0.81 & 0.00 & 0.01 \\
\hline $20: 3 n 9$ & ND & $0.29 \pm 0.25$ & $0.03 \pm 0.11$ & 15.12 & 0.00 & 0.00 & 0.62 & 0.00 \\
\hline n6-PUFA & $33.05 \pm 4.64$ & $32.92 \pm 5.36$ & $37.90 \pm 3.21$ & 4.78 & 0.01 & 0.94 & 0.01 & 0.01 \\
\hline $20: 4 n 6$ (AA) & $26.40 \pm 5.86$ & $27.02 \pm 7.22$ & $31.93 \pm 3.90$ & 3.28 & 0.05 & 0.80 & 0.02 & 0.05 \\
\hline $22: 4 n 6$ & $1.32 \pm 0.95$ & $1.38 \pm 0.90$ & $1.74 \pm 1.01$ & 0.67 & 0.52 & & & \\
\hline $22: 5 n 6$ (DPA) & $3.81 \pm 1.55$ & $3.34 \pm 1.93$ & $2.92 \pm 3.23$ & 0.43 & 0.65 & & & \\
\hline n3-PUFA & $4.17 \pm 3.56$ & $4.37 \pm 5.97$ & $3.75 \pm 1.00$ & 0.07 & 0.93 & & & \\
\hline 22:6n3 (DHA) & $3.86 \pm 3.51$ & $4.13 \pm 5.98$ & $3.47 \pm 0.77$ & 0.08 & 0.92 & & & \\
\hline \multicolumn{9}{|l|}{ PS } \\
\hline
\end{tabular}

Values represent mean $\pm \mathrm{SD}$ ( $n=12$ per group). $\Sigma$ PUFA, sum of all polyunsaturated fatty acids; n6-PUFA, sum of all n6 polyunsaturated fatty acids; n6-PUFA, sum of all n6 polyunsaturated fatty acids; ND, not detected.

showed that memory at $24 \mathrm{~h}$ was inversely correlated with 20:3 $\mathrm{n}-9$ in PC, PE, and PS and positively with 22:6 n-3 in PC, PE, and PI fractions and inversely correlated with DPA in PE fraction, all of them in cerebral cortex. In hippocampus, STL was inversely correlated with DPA from all phospholipid fractions and positively with DHA in PS fraction (Table 3).

\section{DISCUSSION}

This experiment, carried out in rats, studied both biochemical and behavioral consequences of dietary restriction of LCPUFA limited to lactation and the possible reversal effects of a LCPUFA supplementation. Two different dietary schedules were analyzed and compared with a control group. The first group was nursed with a LCPUFA-deficient lactation, and the second group was nursed with a LCPUFA-deficient lactation supplemented with LCPUFA.

Decreased DHA and increased 22:4 n-6 and 22:5 n-6 levels are the classic biochemical FA profile observed in long-term n-3 dietary deficiency, both in adult animals submitted to n-3 FA dietary deficiency in different tissues and brain areas $(5,6)$ and in neonatal and young rats that are born to mothers submitted to this dietary deficiency $(8,9)$. However, in our experimental conditions, a shorter time of n-3 deficiency during part of lactation reflects the same FA profile. In reverse, deficient animals with LCPUFA supplementation showed levels of DHA and DPA similar to the C group, showing the biochemical reversal effect of DHA supplementation on a previous n-3 deficiency FA pattern (24). All of these data suggest that lactation is as important as the prenatal period in LCPUFA brain accretion.

Learning and visual disabilities have been associated with an n-3-deficient FA profile in postnatal long-term deficiency (25) and prenatal deficiency (26). Memory of the D group was poorer than the $\mathrm{C}$ group, whereas memory in the $\mathrm{S}$ group was unaffected, translating that LCPUFA deficiency during lactation also affects learning. It is remarkable that this former 
Table 2. Fatty acid composition of hippocampus (\%, wt/wt)

\begin{tabular}{|c|c|c|c|c|c|c|c|c|}
\hline Fatty acid & $\mathrm{C}$ group & D group & $\mathrm{S}$ group & ANOVA & $p$ & C-D & $\mathrm{C}-\mathrm{S}$ & D-S \\
\hline \multicolumn{9}{|l|}{$\mathrm{PC}$} \\
\hline SFA & $58.34 \pm 1.14$ & $59.40 \pm 5.42$ & $58.97 \pm 1.92$ & 0.65 & 0.72 & & & \\
\hline$\sum$ PUFA & $14.24 \pm 1.02$ & $14.42 \pm 5.24$ & $14.36 \pm 1.12$ & 0.48 & 0.78 & & & \\
\hline $20: 3 n 9$ & $0.01 \pm 0.02$ & $0.08 \pm 0.14$ & $0.10 \pm 0.05$ & 3.49 & 0.04 & 0.07 & 0.02 & 0.54 \\
\hline n6-PUFA & $11.71 \pm 1.01$ & $11.55 \pm 4.06$ & $10.97 \pm 0.78$ & 0.89 & 0.64 & & & \\
\hline 20:4n6 (AA) & $8.34 \pm 0.38$ & $8.33 \pm 3.36$ & $8.37 \pm 0.61$ & 0.37 & 0.83 & & & \\
\hline $22: 4 n 6$ & $0.83 \pm 0.07$ & $0.77 \pm 0.28$ & $1.13 \pm 0.11$ & 18.15 & 0.00 & 0.48 & 0.00 & 0.00 \\
\hline $22: 5 n 6(\mathrm{DPA})$ & $0.98 \pm 1.02$ & $1.36 \pm 0.86$ & $0.53 \pm 0.13$ & 12.33 & 0.00 & 0.25 & 0.18 & 0.02 \\
\hline n3-PUFA & $3.06 \pm 0.41$ & $2.79 \pm 1.18$ & $3.28 \pm 0.35$ & 2.40 & 0.30 & & & \\
\hline 22:6n3 (DHA) & $2.93 \pm 0.33$ & $2.71 \pm 1.16$ & $3.10 \pm 0.33$ & 1.42 & 0.49 & & & \\
\hline \multicolumn{9}{|l|}{$\mathrm{PE}$} \\
\hline SFA & $28.31 \pm 1.13$ & $29.76 \pm 2.23$ & $26.75 \pm 0.96$ & 14.25 & 0.00 & 0.03 & 0.02 & 0.00 \\
\hline$\sum$ PUFA & $53.38 \pm 1.62$ & $53.84 \pm 2.39$ & $55.22 \pm 1.22$ & 5.71 & 0.06 & & & \\
\hline $20: 3 n 9$ & $0.39 \pm 0.25$ & $0.39 \pm 0.72$ & $0.63 \pm 0.07$ & 1.21 & 0.31 & & & \\
\hline n6-PUFA & $30.84 \pm 1.12$ & $32.88 \pm 1.62$ & $30.94 \pm 0.62$ & 12.17 & 0.00 & 0.00 & 0.84 & 0.00 \\
\hline 20:4n6 (AA) & $18.25 \pm 0.46$ & $18.03 \pm 0.53$ & $18.46 \pm 0.42$ & 2.39 & 0.11 & & & \\
\hline $22: 4 n 6$ & $7.61 \pm 0.23$ & $6.77 \pm 0.39$ & $7.63 \pm 0.41$ & 21.33 & 0.00 & 0.00 & 0.90 & 0.00 \\
\hline $22: 5 n 6(\mathrm{DPA})$ & $3.29 \pm 0.89$ & $6.46 \pm 1.26$ & $3.35 \pm 0.43$ & 44.60 & 0.00 & 0.00 & 0.87 & 0.00 \\
\hline n3-PUFA & $22.15 \pm 1.05$ & $20.57 \pm 1.79$ & $23.65 \pm 1.14$ & 14.84 & 0.00 & 0.01 & 0.01 & 0.00 \\
\hline 22:6n3 (DHA) & $21.75 \pm 1.05$ & $20.19 \pm 1.80$ & $23.17 \pm 1.13$ & 13.78 & 0.00 & 0.01 & 0.02 & 0.00 \\
\hline \multicolumn{9}{|l|}{ PI } \\
\hline SFA & $52.38 \pm 2.39$ & $52.46 \pm 4.20$ & $49.19 \pm 2.45$ & 4.30 & 0.02 & 0.95 & 0.02 & 0.02 \\
\hline$\Sigma$ PUFA & $35.90 \pm 1.71$ & $33.87 \pm 4.50$ & $38.18 \pm 2.74$ & 9.17 & 0.01 & 0.13 & 0.08 & 0.00 \\
\hline $20: 3 n 9$ & ND & $0.16 \pm 0.29$ & $0.24 \pm 0.25$ & 7.18 & 0.03 & 0.09 & 0.01 & 0.38 \\
\hline n6-PUFA & $32.34 \pm 1.58$ & $29.36 \pm 3.98$ & $33.92 \pm 3.84$ & 5.62 & 0.01 & 0.04 & 0.25 & 0.00 \\
\hline $20: 4 n 6$ (AA) & $28.11 \pm 2.38$ & $22.57 \pm 6.79$ & $29.20 \pm 5.49$ & 5.37 & 0.01 & 0.01 & 0.61 & 0.00 \\
\hline $22: 4 n 6$ & $1.31 \pm 0.61$ & $1.16 \pm 0.73$ & $3.40 \pm 1.41$ & 19.02 & 0.00 & 0.72 & 0.00 & 0.00 \\
\hline $22: 5 n 6$ (DPA) & $1.86 \pm 1.97$ & $3.73 \pm 2.98$ & $0.56 \pm 0.47$ & 14.41 & 0.00 & 0.04 & 0.13 & 0.00 \\
\hline n3-PUFA & $3.55 \pm 1.63$ & $4.35 \pm 3.67$ & $4.03 \pm 2.22$ & 0.27 & 0.76 & & & \\
\hline 22:6n3 (DHA) & $3.08 \pm 1.51$ & $4.10 \pm 3.53$ & $3.47 \pm 2.00$ & 0.50 & 0.61 & & & \\
\hline \multicolumn{9}{|l|}{ PS } \\
\hline SFA & $48.79 \pm 2.05$ & $51.07 \pm 5.07$ & $46.34 \pm 4.20$ & 4.14 & 0.02 & 0.17 & 0.14 & 0.00 \\
\hline$\Sigma$ PUFA & $36.84 \pm 2.50$ & $34.59 \pm 6.16$ & $38.05 \pm 4.18$ & 1.75 & 0.19 & & & \\
\hline $20: 3 n 9$ & $0.03 \pm 0.07$ & $0.14 \pm 0.25$ & $0.27 \pm 0.13$ & 6.45 & 0.00 & 0.11 & 0.00 & 0.07 \\
\hline n6-PUFA & $14.19 \pm 1.57$ & $16.21 \pm 2.92$ & $14.59 \pm 1.73$ & 7.39 & 0.02 & 0.03 & 0.65 & 0.08 \\
\hline $20: 4 n 6(\mathrm{AA})$ & $4.65 \pm 0.55$ & $4.66 \pm 2.45$ & $4.90 \pm 0.76$ & 0.11 & 0.89 & & & \\
\hline $22: 4 n 6$ & $4.14 \pm 0.40$ & $3.28 \pm 0.45$ & $4.28 \pm 0.84$ & 9.09 & 0.00 & 0.00 & 0.56 & 0.00 \\
\hline $22: 5 n 6$ (DPA) & $4.57 \pm 1.26$ & $7.05 \pm 2.10$ & $4.42 \pm 0.90$ & 11.25 & 0.00 & 0.00 & 0.81 & 0.00 \\
\hline n3-PUFA & $22.61 \pm 2.06$ & $18.24 \pm 4.54$ & $23.18 \pm 3.02$ & 7.51 & 0.00 & 0.00 & 0.68 & 0.00 \\
\hline 22:6n3 (DHA) & $22.31 \pm 1.97$ & $17.61 \pm 4.65$ & $22.66 \pm 3.00$ & 10.88 & 0.00 & 0.00 & 0.80 & 0.00 \\
\hline
\end{tabular}

Values represent mean $\pm \mathrm{SD}(n=12$ per group).

adverse effect is reversed when a dietary supplement that contains DHA and AA is supplied to D animals. The functional reversibility of n-3 deficiency by adding DHA to the diet was described previously $(27,28)$. Taking into account that retina and brain FA profiles have similar changes according to $n-3$ content of diet (29), the learning differences found in our study could be explained on the basis of presumed visual disturbances. However, the exploratory behavior in the training session of the passiveavoidance test did not show differences among groups. Therefore, visual differences would not explain the poorer retention memory found in D animals, and, therefore, memory differences could be more related to brain FA composition.

Considering that PS and PE fractions are those with higher levels of DHA (30), it could be hypothesized that these phospholipids could be involved in cognitive functions assigned to cerebral cortex and hippocampus such as learning. Learning was correlated directly to DHA in PS from hippocampus and in PC, PE, and PI from cerebral cortex and inversely correlated to both 20:3 n-9 and DPA in PC and PE fractions from cerebral cortex. All of these data confirm the importance of these brain areas in memory but, moreover, the phospholipid fractions involved, PE probably being more important than PS fraction. The physiologic bases of learning deficits described in $n-3$ deficiency have been related to changes in lipid matrix properties and neurotransmission. The DPA, lacking a double bond near the chain methyl end, induces some differences in lipid matrix properties that contain DPA instead of DHA. The DHA-containing lipid matrix is more flexible at the methyl end and has a higher electron density near the lipid-water interface (31). Alterations in dopaminergic (32) and cholinergic (33) neurotransmission have been described in $\mathrm{n}-3-$ deficient animals related to brain functional deficits. The possible relationships among DHA content in different phospholipid fractions from different brain areas and the alterations in brain neurotransmission remain unclear.

\section{CONCLUSION}

In conclusion, DPA, a known biochemical index of n-3 dietary deficiency, is not a suitable functional substitute of 


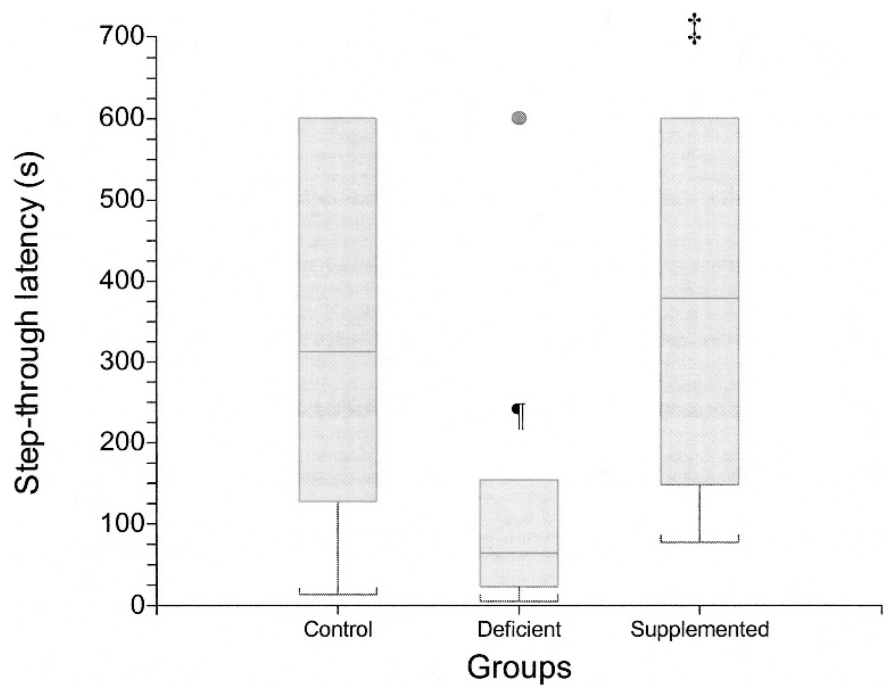

Figure 1. Effects of LCPUFA deficiency and supplementation on learning measured by passive-avoidance test in rats $24 \mathrm{~h}$ after the aversive event during lactation. Values represent median $\pm \mathrm{IQR}$. Kruskal-Wallis test, $\chi^{2}=7.22, p=$ $0.027(n=36)$. 【[Deficient vs Control) $p=0.07)$, $\ddagger$ Supplemented vs Deficient $(p=0.02)$.

Table 3. Correlations between brain LCPUFA from different phospholipids fractions and learning measured by STL in the passive-avoidance test

\begin{tabular}{cclrc}
\hline Brain area & Lipid fraction & \multicolumn{1}{c}{ Fatty acid } & \multicolumn{1}{c}{$r$} & \multicolumn{1}{c}{$p$} \\
\hline Cerebral cortex & PC & 20:3n9 & -0.340 & 0.046 \\
& & $22: 6 \mathrm{n} 3$ (DHA) & 0.349 & 0.040 \\
& PE & $20: 3 \mathrm{n} 9$ & -0.480 & 0.003 \\
& & $22: 5 \mathrm{n} 6$ (DPA) & -0.446 & 0.007 \\
& & $22: 6 \mathrm{n} 3$ (DHA) & 0.485 & 0.003 \\
Hippocampus & PI & $22: 6 \mathrm{n} 3$ (DHA) & 0.384 & 0.023 \\
& PS & $20: 3 \mathrm{n} 9$ & -0.399 & 0.020 \\
& PC & $22: 5 \mathrm{n} 6$ (DPA) & -0.519 & 0.002 \\
& PE & $20: 5 \mathrm{n} 3$ & -0.418 & 0.012 \\
& & $22: 5 \mathrm{n} 6$ (DPA) & -0.468 & 0.005 \\
& PI & $22: 5 \mathrm{n} 6$ (DPA) & -0.354 & 0.037 \\
& PS & $22: 5 \mathrm{n} 6$ (DPA) & -0.353 & 0.038 \\
& & $22: 6 \mathrm{n} 3$ (DHA) & 0.329 & 0.054 \\
\hline
\end{tabular}

Values represent the Spearman correlation coefficients $(r)$ and the level of significance $(p) ; n=12$ per group.

DHA. In this work, young rats with a deficient supply of n-3 FA limited to the lactation period presented poor memory retention in passive-avoidance test directly correlated to DHA and inversely correlated to DPA brain levels. Both biochemical and functional consequences of this dietary deficiency were reversed when a supplement of DHA was administered to deficient animals.

Acknowledgments. We thank M. José Rozas, M. Angeles Gavilán, and Ester Urruticoechea for helpful technical assistance.

\section{REFERENCES}

1. Sastry PS 1985 Lipids of nervous tissue: composition and metabolism. Prog Lipid Res 24:69-176

2. Spector AA, Yorek MA 1985 Membrane lipid composition and cellular function. J Lipid Res 26:1015-1035

3. Connor WE, Neuringer E, Lin DS 1990 Dietary effects on brain fatty acid composition: the reversibility of n-3 fatty acid deficiency and turnover of docosahexaenoic acid in the brain, erythrocytes, and plasma of rhesus monkeys. J Lipid Res 31:237247

4. Bourre JM, Dumont OS, Piciotti MJ, Pascal GA, Durand GA 1992 Dietary alphalinolenic acid deficiency in adult rats for 7 months does not alter brain docosahexaenoic acid content, in contrast to liver, heart and testes. Biochim Biophys Acta 1124:119-122

5. Ehrstrom M, Harms-Ringdahl M, Alling C 1981 Osmotic fragility and fluidity of erythrocyte membranes from rats raised on an essential fatty acid deficient diet. Biochim Biophys Acta 644:175-182

6. Murthy M, Hamilton J, Greiner RS, Moriguchi T, Salem N Jr, Kim HY 2002 Differential effects of n-3 fatty acid deficiency on phospholipid molecular species composition in the rat hippocampus. J Lipid Res 43:611-617

7. Guesnet P, Pascal G, Durand G 1988 Effects of dietary alpha-linolenic acid deficiency during pregnancy and lactation on lipid fatty acid composition of liver and serum in the rat. Reprod Nutr Dev 28:275-292

8. Ward G, Woods J, Reyzer M, Salem N Jr 1996 Artificial rearing of infant rats on milk formula deficient in $\mathrm{n}-3$ essential fatty acids: a rapid method for the production of experimental n-3 deficiency. Lipids 31: 71-77

9. Ward GR, Huang YS, Bobik E, Xing HC, Mutsaers L, Auestad N, Montalto M Wainwright P 1998 Long-chain polyunsaturated fatty acid levels in formulae influence deposition of docosahexaenoic acid and arachidonic acid in brain and red blood cells of artificially reared neonatal rats. J Nutr 128:2473-2487

10. Innis SM 2000 Essential fatty acids in infant nutrition: lessons and limitations from animal studies in relation to studies on infant fatty acid requirements. Am J Clin Nutr 71(suppl 1):238S-244S

11. Fidler N, Sauerwald T, Pohl A, Demmelmair H, Koletzko B 2000 Docosahexaenoic acid transfer into human milk after dietary supplementation: a randomized clinical trial. J Lipid Res 41:1376-1383

12. Yeh YY, Yeh SM, Lien EL 1998 Modification of milk formula to enhance accretion of long-chain n-6 and n-3 polyunsaturated fatty acids in artificially reared infant rats. Lipids 33:513-520

13. Ward GR, Huang YS, Xing HC, Bobik E, Wauben I, Auestad N, Montalto M, Wainwright PE 1999 Effects of gamma-linolenic acid and docosahexaenoic acid in formulae on brain fatty acid composition in artificially reared rats. Lipids 34:10571063

14. Horrocks LA, Yeo YK 1999 Health benefits of docosahexaenoic acid (DHA) Pharmacol Res 40:211-225

15. Catalan J, Moriguchi T, Slotnick B, Murthy M, Greiner RS, Salem N Jr 2002 Cognitive deficits in docosahexaenoic acid-deficient rats. Behav Neurosci 116:1022-1031

16. Carrie I, Smirnova M, Clement M, DE JD, Frances H, Bourre JM 2002 Docosahexaenoic acid-rich phospholipid supplementation: effect on behavior, learning ability, and retinal function in control and n-3 polyunsaturated fatty acid deficient old mice. Nutr Neurosci 5:43-52

17. Eichenbaum H 1997 Declarative memory: insights from cognitive neurobiology Annu Rev Psychol 48:5487-5572

18. Henke K, Weber B, Kneifel S, Wieser HG, Buck A 1999 Human hippocampus associates information in memory. Proc Natl Acad Sci USA 96:5884-5889

19. García-Calatayud S, Ruiz JI, García-Fuentes M, Dierssen M, Florez J, Crespo PS 2002 Long-chain polyunsaturated fatty acids in rat maternal milk, offspring brain and peripheral tissues in essential fatty acid deficiency. Clin Chem Lab Med 40:278-284

20. Folch J, Lees M, Sloane-Stanley GH 1957 A simple method for the isolation and purification of total lipids from animal tissues. J Biol Chem 226:497-509

21. Ruiz JI, Ochoa B 1997 Quantification in the subnanomolar range of phospholipids and neutral lipids by monodimensional thin-layer chromatography and image analysis. J Lipid Res 38:1482-1489

22. Lepage G, Roy CG 1986 Direct transesterification of all classes of lipids in a one step reaction. J Lipid Res 27:114-120

23. Shagal A 1993 Passive avoidance procedures. In: Shagal A (ed) Behavioural Neuroscience. A Practical Approach. IRL Press, Oxford, pp 49-56

24. Moriguchi T, Loewke J, Garrison M, Catalan JN, Salem N Jr 2001 Reversal of docosahexaenoic acid deficiency in the rat brain, retina, liver, and serum. J Lipid Res 42:419-427

25. Moriguchi T, Greiner RS, Salem N Jr 2000 Behavioral deficits associated with dietary induction of decreased brain docosahexaenoic acid concentration. J Neurochem 75:2563-2573

26. Schiefermeier M, Yavin E 2002 n-3 Deficient and docosahexaenoic acid-enriched diets during critical periods of the developing prenatal rat brain. J Lipid Res 43:124-131

27. Carrie I, Clement M, de Javel D, Frances H, Bourre JM 2000 Phospholipid supplementation reverses behavioral and biochemical alterations induced by $n-3$ polyunsaturated fatty acid deficiency in mice. J Lipid Res 41:473-480

28. Ikemoto A, Ohishi M, Sato Y, Hata N, Misawa Y, Fujii Y, Okuyama H 2001 Reversibility of n-3 fatty acid deficiency-induced alterations of learning behavior in the rat: level of n-6 fatty acids as another critical factor. J Lipid Res 42:1655-1663

29. Wang N, Wiegand RD, Anderson RE 1992 Uptake of 22-carbon fatty acids into rat retina and brain. Exp Eye Res 54:933-939

30. Green P, Yavin E 1996 Fatty acid composition of late embryonic and early postnatal rat brain. Lipids 31:859-865

31. Eldho NV, Feller SE, Tristram-Nagle S, Polozov IV, Gawrisch K 2003 Polyunsaturated docosahexaenoic vs docosapentaenoic acid-differences in lipid matrix properties from the loss of one double bond. J Am Chem Soc 125:6409-6421

32. Wainwright PE 2002 Dietary essential fatty acids and brain function: a developmental perspective on mechanisms. Proc Nutr Soc 61:61-69

33. Aid S, Vancassel S, Poumes-Ballihaut C, Chalon S, Guesnet P, Lavialle M 2003 Effect of a diet-induced n-3 PUFA depletion on cholinergic parameters in the rat hippocampus. J Lipid Res 44:1545-1551 